\title{
Contemplating an Evolutionary Approach to Entrepreneurship
}

\author{
Colin Jones \\ Lecturer in Entrepreneurship \\ University of Tasmania
}

School of Management, Private Bag 16,

Hobart 7001, Tasmania, Australia

tel: (+61)362262826, fax: (+61)362262808,

email: Colin.Jones@utas.edu.au 


\title{
Contemplating an Evolutionary Approach to Entrepreneurship
}

\begin{abstract}
:
This paper explores that application of evolutionary approaches to the study of entrepreneurship. It is argued an evolutionary theory of entrepreneurship must give as much concern to the foundations of evolutionary thought as it does the nature entrepreneurship. The central point being that we must move beyond a debate or preference of the natural selection and adaptationist viewpoints. Only then can the interrelationships between individuals, firms, populations and the environments within which they interact be better appreciated.
\end{abstract}

KEYWORDS: Entrepreneurship, Selection, Lamarckism, Interaction, and Replication

\section{INTRODUCTION}

During recent times, the frequency of calls for researchers of entrepreneurship to adopt an evolutionary approach has increased. Two of the domain's leading journals (i.e. Entrepreneurship Theory and Practice and the Journal of Business Venturing) have organised special editions devoted to consideration of the increasing application of evolutionary theories to the study of entrepreneurship. Appropriately, the work of Howard Aldrich strongly influences the content and contributors of these special editions. Aldrich's (1999) articulation of a generic evolutionary framework to advance our understanding of social change is perhaps destined to become a landmark contribution within the developing field of entrepreneurship research. Yet, despite the breadth of its contribution, many questions remain unresolved, many raised by Aldrich himself in his concluding 'invitation’ chapter. This paper accepts the challenge of Aldrich's challenge to further explore the application of evolutionary theory to the emergence and disappearance 
of organizational entities. In doing so, this paper deliberately adopts a very eclectic approach, attempting to synthesize ideas that seemingly remain isolated. The journey of confronting the problems that have prevented the development of a legitimate evolutionary approach to the study of entrepreneurship is one requiring much compromise.

This paper is structured in the following manner. First, the importance of an evolutionary approach to entrepreneurship research is considered. Second, the prerequisites of an evolutionary approach are discussed. Third, problematic issues that remain contested are explored through consideration of areas of emerging consensus. Fourth, the nature of empirical evidence required to progress the development of an evolutionary approach to entrepreneurship research is discussed. In keeping with the Aldrichian spirit, the paper concludes by drawing out the implications that arise from this discussion and presents more questions that remain unanswered.

\section{EVOLUTIONARY THEORY AND ENTREPRENEURSHIP}

Entrepreneurship research represents a domain of enquiry that is at present "anchored in the disciplines" of economics, sociology, organizational theory, and psychology (Davidsson, Low \& Wright, 2001: 14). To many, entrepreneurship has yet to emerge as a respected discipline in its own right. This is disappointing given the importance of entrepreneurship research to addressing the issues economic and social change. In 1988, Murray Low and Ian MacMillan raised six specific concerns relating to past and future research into entrepreneurship. The six specific areas of critical importance to entrepreneurship researchers reviewed were: purpose, theoretical perspective, focus, level of analysis, time frame, and methodology. These specific issues have generally received isolated attention, with the obvious exception being the increased use of 
evolutionary theories within entrepreneurship research. This approach has enabled an increased focus on not only context and process, but also causal explanations relating to the outcomes of entrepreneurial behaviour.

In contrast to calls for a "predictive theory of the behavior of entrepreneurs" (Amit, Glosten \& Muller, 1990: 1232), non-predictive evolutionary perspectives enable the specific issues raised by Low and MacMillan (1988) to be fully accommodated, thereby advancing the cause of entrepreneurship as a distinct research discipline. Examples include; Aldrich and Martinez’s (2001) direct response to Low and MacMillan; Aldrich’s (1999) use of an evolutionary perspective to consider organizational change; Brittain's (1994) ecological explanation of community evolution; Baum and Singh's (1994) consideration of the replicating and interacting hierarchical processes; Murmann and Tushman's (2001) assertion that social context is an important determinate of entrepreneurial activity; and Lumsden and Singh's (1990) discussion of organizational speciation. These examples demonstrate the widespread use of evolutionary theories to research various aspects of entrepreneurship.

Throughout these exemplars attention is paid to purpose (a general focus on how entrepreneurship furthers economic progress); theoretical perspective (a trend from strong to weak selection, ensuring adaptive and environmental change factors are simultaneously considered); focus (greater emphasis placed upon understanding the context and process of entrepreneurship); level of analysis (consideration of hierarchical interacting relationships at which selection occurs, for example, the ecosystem, communities of practice, populations of firms, firms, routines, individuals); time frame (greater appreciation of cohort and period effects); and methodology (acceptance of multiple methods and a greater importance given to causality). An evolutionary approach 
accommodates and places great emphasis on all six issues, however, the nature and design of evolutionary approaches remains quite varied.

Differences of opinion remain within the literature as to what constitutes an evolutionary approach or theory. The original ideas of Lamarck and Darwin clearly have lost their shape through repeated reinterpretation and transfer from one domain to another. Rather than attempt a top-down unravelling of what exists, a more profitable approach may be to proceed from the bottom-up, determining the prerequisites of an appropriate evolutionary approach to the study of entrepreneurship.

\section{PREREQUISITES OF AN EVOLUTIONARY THEORY}

To address this issue, two perspectives are considered, one economic and the other, philosophical. Economic theory represents the most enduring of theoretical bases upon which entrepreneurship research has been guided. While acknowledging the difficulties of classifying all manner of items, a taxonomy of economic evolution is provided by Hodgson (1993). Two broad perspectives of evolution are considered, those being developmental and genetic evolution. The developmental perspective adopts the view that evolution would progress through a series of stages, as if the outcome was predicable. An example being the Marxian idea that a socio-economic system evolves from a primitive form of communism, to classical antiquity, to feudalism and capitalism, to socialism and communism. Hodgson uses the term genetic in a non-biological way to mean an emphasis upon determining causality with regards the interacting components of a system. Within the genetic perspective, ontogenetic and phylogenetic categories exist.

Ontogenetic evolution (e.g. Schumpeter) has a weak focus on selection mechanisms and is characterised by a belief that a fixed genetic instruction set (moderated by environmental conditions) is representative of a (single) entities set of evolutionary 
possibilities. In contrast, phylogenetic evolution places great emphasis on selection to establish causality. The works of Thorstein Veblen provide the earliest example of phylogenetic evolution being proposed in the economic sphere. Hodgson (1993) notes the argument against the ontogenetic position of consummation in economic evolution by Veblen (1919) in favour an evolutionary explanation related to selection within populations and focused on causality.

So, from an economic perspective, evolution can take the form of a developmental theory that presumes the advancement from one state to another. It also can be considered from a genetic perspective, with two different approaches. Firstly, it can be considered ontogenetic, where the outcomes of change for a particular entity are seemingly predetermined with only environmental influence altering the eventual equilibrium position. Alternatively, the process of phylogenetic evolution allows for the "complete and ongoing evolution of a population” (Hodgson, 1993: 40) with acceptance that the generative mechanisms that determine structural change may also be altered through a blind (and differential) process of selection. This second evolutionary perspective is one developed by philosophers of science. At the heart of their work is the central issue of what constitutes an evolutionary theory.

\section{MINIMAL EVOLUTIONARY REQUIREMENTS}

The recent philosophical musings of several prominent academics has advanced the basic minimal requirements of evolutionary theory and also raises the issue of Lamarckism as a potential strange bedfellow for Darwinism within the socioeconomic sphere. This section will consider the minimal requirements for a sound evolutionary theory. With reference to Darwin's principle of natural selection, Lewontin articulated three evolutionary principles. The first principle being phenotypic variation where 
different entities in a population have "different morphologies, physiologies, and behaviours" (Lewontin, 1970: 1). The second principle being differential fitness, or, the differential survival and reproduction of phenotypes in different environments. The third principle being heritable fitness, or, the "correlation between parents and offspring in the contribution of each future generations". Lewontin proposed that any population displaying these principles would undergo transformation.

Closely related was Campbell’s (1965) blind-variation-selective-retention process, which aimed to explain the general evolutionary process occurring within and between entities. This was to become the foundation of Campbell's 'evolutionary epistemology', a phrase he coined in 1974 (Plotkin, 1993). Importantly, Campbell successfully championed the long held view ${ }^{1}$ that a general theory of evolution was indeed applicable beyond the boundaries of biology (Hodgson, 2003a). Eventually, the perceived ubiquity of blindvariation-selective-retention process led Dawkins (1983) to coin the phrase 'Universal Darwinism'. Hodgson (2003b: 90) states that "the difference between natural and social evolution was in the units of selection and in the details of the evolution process, not in the exclusion of variation, inheritance [i.e. retention], or selection from the social sphere”. An alternative, but complementary view (Plotkin, 1993) to that of the blind-variationselective-retention process also exists. That is David Hull's proposition that an evolutionary theory must incorporate two specific entities, a replicator and a interactor. These terms are defined by Hull (1988: 408) as any "entity that passes on its structure largely intact in successive replications" and any "entity that interacts as a cohesive whole with its environment in such a way that this interaction causes replication to be differential”, and are widely accepted.

However, while Darwinism provides a rigorous theory and has at its heart a focus upon the problem of causality, the challenge remains to identify a process of transmission 
from within which "selected variants are moved about in space and conserved in over time” (Plotkin, 1993: 84). Indeed, Durham suggests that this challenge is but one of five essential requirements of any evolutionary system, illustrated in Figure 1 below.

Insert Figure 1 about here

Determining the units of transmission within the socio-economic domain has long represented a complex debate. There would now appear to be convincing arguments ${ }^{2}$ within the current literature that habits and routines are suitable representative units of transmission. Sources of variation are typically accounted for by means of innovation, imitation, and new entrants. To establish a process of cumulative causation, it is vital that a mechanism of transmission is identified and explained. This however remains a challenging task for evolutionary theorists. Knudsen (2002: 451) implores researchers "to account for the mechanism of transmission and the infusion of new but not limited variation around the mean of what turned out to provide an advantage”. Similarly, Murmann (2003: 11) suggests the challenge that remains for any evolutionary explanation "is to specify how variants are introduced, how selection leaves behind variants that were not as fit according to the prevailing selection criteria (criteria that in turn need to be identified), and how some variants are retained over time to create a historical trajectory or genealogy captured by decent with modification”.

What becomes evident is that in order to meet the minimal requirements of an evolutionary theory in the socio-economic domain, only certain forms of phylogenetic economic evolution satisfy the requirements of Lewontin, Campbell, Hull, and Durham. Across these perspectives is the need for variation to be blind (in the sense that we cannot 
predict the future), random, or purposive in character, selection must be differential, and a mechanism must exist through which favoured characteristics are retained in a population and passed on to other generations. The alternative developmental perspective is tolerant of and expecting the presence of an eventual equilibrium. Likewise, Hodgson (1993) also notes that Schumpeter uses the term evolutionary in the 'developmental' sense while also rejecting any analogy with natural selection. Lastly, Hodgson also notes the tendency of Hayek's (1988) spontaneous order to gravitate towards to equilibrium. Also, Hayek’s support of methodological individualism is problematic, suggesting an eventual focus upon one sole level of selection. Essentially, Hayek's evolutionary theories are consummatory with creativity and ongoing variety restoring order, rather than continually providing the seeds discontent. The varied and related minimal requirements of an evolutionary approach can be illustrated in Figure 2 below. Importantly, the degree of consistency that is present in the seminal works of Campbell, Lewontin, Durham, and Hull are all derived from a Darwinian perspective.

Insert Figure 2 about here

Since the verbose writings of Veblen, the presence of Darwinian selection is accepted amongst old institutional economists (e.g. Hamilton, 1953 and Hodgson, 2003b) and increasingly in other areas other social sciences. In contrast to orthodox economics, this school of thought is comfortable to develop an evolutionary perspective without the need of equilibrium assumptions. The recent works of Geoffrey Hodgson in renewing Veblen's post-Darwinian thoughts are important with regards advancing an evolutionary theory through which entrepreneurial behaviour is explainable. To address this point, it is 
first necessary to briefly consider the nature and relationships between Darwinian and Lamarckian ideas and how they relate to the neo-Darwinian position. This is perhaps best achieved by noting briefly how these theories have been applied in organizational, economic and entrepreneurship literature. Hodgson (2003a: 95) defines Darwinism as “a causal theory of evolution in complex or organic systems, involving the inheritance of genotypic instructions by individual units, a variation of genotypes, and a process of selection of the consequent phenotypes according to their fitness in their environment”. Hodgson continues on to define Lamarckism as 'a doctrine admitting the possibility of the (genotypic) inheritance of acquired (phenotypic) characters by individual organisms in evolutionary processes’.

\section{PROBLEMATIC ISSUES AND AREAS OF EMERGING CONSENSUS}

The processes of Darwinian selection and Lamarckian adaptation tend to anchor opposing sides of a debate that has prevailed for decades within the economic and organizational theory literatures (Lewin \& Volberda, 1999). This debate centres upon the respective influence of the environment to select under performing firms from an industry, versus the ability of firms to arrest the process of natural selection through adaptation to the their changing environment. Lamarck (1984: 70) felt that the "progress in complexity of an organisation exhibits anomalies here and there ... due to the influence of environment and of acquired habits”. Generally, socioeconomic evolution has been considered Lamarckian in nature (e.g. Nelson \& Winter 1982) due to the fact that it is purposive (Rescher, 1977). That said, sound arguments that socioeconomic evolution is first and foremost Darwinian exist (Dollimore, 2003), and these will be considered in more detail throughout this paper. 
It is however perhaps due to the outright rejection of Lamarckian evolution by biologists in favour of Charles Darwin's theory of natural selection (i.e. modification by decent), the two views have assumed a degree of rivalry. This is disappointing given the desire of Campbell (1965) to advance a general evolutionary theory of the processes occurring within and between entities. As a result, those who support the population ecology views (e.g. Hannan \& Freeman, 1977) often to fail to consider the likelihood of firm level adaptation. Alternatively, advocates of contingency theory (e.g. Donaldson, 1988) and strategic choice perspectives (Miles \& Snow, 1994) continue to assert that variation arises from environmental change and that firm's are capable of securing a fit with their operating environment. The middle ground of this debate belongs to those pragmatic researchers who seek to understand the interrelated process of selection and adaptation (e.g. Levinthal, 1991; Haveman, 1992; Amburgey, Kelly, \& Barnett, 1993; Bruderer \& Singh, 1996; Rao, 1998). Such approaches tend to acknowledge both Darwinian and Lamarckian processes. Charles Darwin was at least tolerant of Lamarckian evolution (Hodgson, 2001) on the proviso that "acquired characters are inherited only rarely and weakly" (Gould, 2002: 354). On this basis, Darwin noted, "that natural selection has been the most important, but not the exclusive, means of modification" (1901: 4). Others suggest that Darwin eventually became very reliant upon Lamarck's acquired characteristics $^{3}$ to overcome a potentially fatal challenge to his mechanism of heredity (Koestler, 1978). Therefore, an evolutionary theory must also address the occurrence of variations associated with adaptive behaviours within evolving systems.

Importantly, Veblen's Darwinism also incorporated aspects of Lamarckism, specifically, the inheritance of acquired characters (Hodgson, 1993). However, following Veblen's death in 1929, the unpopularity of social Darwinism ${ }^{4}$ and the increasing acceptance of the term neo-Darwinism in society, the further development of Veblen's 
post-Darwin economics where thwarted. The term neo-Darwinian has existed since Darwin's protégé George Romanes used it to describe those who explicitly rejected the possibility of the inheritance of acquired characteristics as being "more Darwinian than Darwin” (Wilkins, 2001: 161-162). Within the domain of socio-economic evolution, Weismannism is the term used to describe the neo-Darwinist position. Essentially, the mechanisms through which organizational structures are created remain unaltered through interaction with the operating environment. This view is more in line with the process of natural selection operating upon firms within a given population. Therefore, when adopting a Darwinist perspective, the previously dominant position that Weismannism and Lamarckism are mutually exclusive is less valid. This is because there is little difference between the causal structures of both forms of evolution (Knudsen, 2002: 451) with "the only thing that sets Lamarckian selection apart from neo-Darwinian selection is that replicators are modified due to information received from their carriers, the interactors”.

The recent work of Knudsen (2001) and Hodgson (2001) suggests that we can work towards a more intuitive, and more Darwinian explanation of the processes of firm/population transformation that embodies both Weismannian and Lamarckian processes. From this perspective, Lamarckian evolution nests within a Darwinian framework that also accommodates the process of natural selection. Such an approach is consistent with Williams (1996: v) who states that "when recognised, adaptation should be attributed to no higher a level of organization than is demanded by the evidence. Natural selection is the only acceptable explanation for the genesis and maintenance of adaptation". The focus is not purely upon environmental elements (i.e. political, economic, socio-cultural, technological, and international forces) to determine fitness, but rather the interplay between the environment and the firm's activities that play the role of interactors. However, clearly issues remain unresolved that prevent the advancement of an 
evolutionary theory through which entrepreneurial processes and outcomes can be better understood. "The next step in entrepreneurial research is very clear: we need to stop a posteriori explaining the interaction between strategy and environment and between process, context, and outcomes” (Aldrich \& Martinez, 2001: 53).

\section{THE NEED FOR EMPIRICAL EVIDENCE}

The task at hand would appear the need to generate theory that can be later verified and tested for accuracy. So many questions remain unanswered and without consensus. This section will consider four important issues that currently provide roadblocks to the development of a sound evolutionary theory. The first is the contentious issue of whether Lamarckian evolution should be assumed to better explain socioeconomic evolution than Darwinism. The second issue relates to the nature of selection at its multiple forms within and outside social entities. The third issue is concerned with what elements of an entity interact to with the environment in such a way that favourable (or non-favourable) selection occurs. The last issue to be discussed is that of the nature of replication. It is argued that at present, our general understanding of how all four processes exist (and are interrelated) as applied to entrepreneurship research is insufficient to support the development of a sound evolutionary theory of entrepreneurship. The remainder of this section attempts to highlight areas of confusion that are increasingly less serviced by conceptual theorizing. It is from empirical research that the way forward must be achieved. Lets us briefly consider the four issues raised thus far and then the possible relationships between them.

At the heart of Lamarckism are two specific laws that Jean-Baptiste Lamarck outlined in his most famous work, the Philosophie Zoologique published in 1809. The first law, called the 'law of use and disuse' suggests that new organs, or modified old ones, 
occur spontaneously through need satisfied by use and disappear through disuse. The second law, called the 'law of inheritance of acquired characteristics' maintains that any such change is heritable. Consequently, Lamarckism provides the means through which continuous and gradual change can occur within organisms through which a better degree of fitness is achieved vis-à-vis their environments. The underlying assumption is that Lamarckism is a function of the organism's physiological needs that are continually altered through interaction with the environment.

In the past it has not been uncommon for work to be presented as Lamarckian in nature (e.g. Nelson \& Winter, 1982). As a result, it would seem that the term Lamarckism is all to easily applied within work where social learning and intentionality are taken as given. That is, where it is accepted that humans and the organizational forms they create and operate are capable of searching for and selecting in favor of new forms of variation that are perceived at some point in time to advance their situation. As a result, social change achieved through the generic evolutionary processes of variation, selection and retention is increasingly described as Lamarckism ${ }^{5}$. However, the emphasis is clearly more related to Lamarck's first law than the second law. To demonstrate empirically the role and frequency of Lamarckism with the domain of socioeconomic evolution, the inheritance of acquired characters from one generation to another must be shown to occur.

The challenge that remains, regardless of whether one accepts that the process of Lamarckism nests within an overarching Darwinian framework (Knudsen, 2002), is to separate the occasions when acquired characters ${ }^{6}$ are retained within the life of a social entity and when they are passed on to another generation of that entity. It is argued that the failure to do so will add a burden to those researchers who wish to develop a truly sound evolutionary account for socioeconomic change. Both laws must be accounted for, not merely the presence of acquired characters. Lets explore further the issue by way of 
example to illustrate the present dilemma that accompanies current assumptions that socioeconomic evolution is inherently Lamarckian.

Consider the Hobart pizza industry that has emerged over the past 35 years. Of the 100 plus firms that have contested this industry, some pioneering foundings have survived to this day. Many have failed, and many have entered the industry with prior experience and/or knowledge gained from past employment. Early on during the formation of the industry, relational ties between the predominately Italian pioneers were strong. Knowledge related to improvements and the nature of how best to operate a pizzeria was shared frequently at weekly social occasions. As the industry developed, relational ties weakened as the population density increased and competition increased. For those new entrants that were not part of the initial network of pioneers, learning how best operate their pizzeria was achieved through either employment within the industry or through (partial) imitation of businesses practices that by and large were quite transparent. Over time, the survival of many, but not all entrants can be explained by Lamarckian evolution.

It can be clearly observed that many past employees of the pioneers who worked in operations that continually acquired characters that (apparently) increased fitness in the emerging industry were able to spin-off successful pizzerias themselves. Further, many of the spin-off's employees were able to start up pizzerias within which the practices of the initial pioneers were present. Clearly, both of Lamarck’s laws are present with evidence of the firms acquiring specific characters that they deemed useful and those characters being directly inherited by future generations of pizzeria owners. For those pizzerias that were not responsible for any spin-offs, the application of Lamarckism to explain their development is problematic due to the lack of evidence regarding the heritability of their acquired characters. It is argued that at present a failing of Lamarckian explanations of socioeconomic evolution is the suggestion that imitation from afar is sufficient to account 
for the inheritance of acquired characters from one firm to another. The alternative explanation offered is that, in the absence of more specific evidence regarding the transmission of acquired characters, Darwinian specific processes are best used to account for the adaptation of social entities whose operations are relatively isolated from other industry participants.

Such an alternative explanation can be outline with reference to Baldwinian evolution. Deacon (1997: 322) notes “Baldwin’s theory explains how behaviors can effect evolution, but without the necessity of claiming that responses to environmental demands acquired during one's lifetime could be passed directly to one’s offspring”. Baldwin's 'A New Factor in Evolution', published 1896, sought to refute Lamarckism through claiming that the context of natural selection could be modified (for future generations) due to the process of learning and behavioral flexibility. Baldwin’s Darwinian inspired concept was however to many "a notion lying on the borderline of Lamarckism” (Plotkin, 1993: 6). It however fits in with other Darwinian based explanations of adaptive survival, such as genetic assimilation (e.g. Waddington, 1969) and adaptive radiation ${ }^{7}$ (Baldwin, 1896). The point is, to ignore accepted Darwinian explanations of intentional adaptation to the environment in favor of Lamarckian explanations makes it all the more difficult to unite the adaptationist and selection viewpoints. Both sides can propose explanations of phenotypic plasticity through which adaptive behaviour results in reduced selection pressure. However, it would seem we have much ground to recover to again maintain Darwin's (if begrudging) assimilation of Darwinian and Lamarckian processes to explain the ongoing evolution of entities. This past failure to dig deeper also prevents closer analysis of how selection forces impact evolution.

Selection that produces evolution has been defined "as repeated cycles of replication, variation, and environmental interaction so structured that environmental 
interaction causes replication to be differential” (Hull, Langman \& Glenn, 2001: 53). Within organizational studies, selection is typically thought of as external or internal forces (to a firm) "that differentially select or selectively eliminate certain types of variations” (Aldrich, 1999: 26). It is quite often assumed such forces ensure conformity to instutionalized norms and adherence to past (internal) selection criteria. However, a risk of ignorance remains ever present when selection is considered to primarily perform a stabilizing role within populations, given that it frequently behaves in different ways. Grant (1985) and Amburgey, Dacin and Kelly (1994) suggest that external selection processes can be considered in three general patterns, stabilizing, directional, and disruptive. When attempting to reconcile the outcomes of various learning processes, it is critical that the nature and the type of selection occurring with the population is understood. To not do so would be to invite misinterpretation of any future data.

For example, returning to the Hobart pizza industry, it can be observed that the most influential selection forces that shaped the evolution of the industry were directional and disruptive selection forces. The arrival of the first nationwide franchise chain increased the level of primary demand for pizza and changed the times when pizza was consumed. Those firms capable of following the lead of the very visible practices introduced by industry leaders seemed to benefit from the increasing demand for pizza (i.e. directional selection). Alternatively, the number of firms contesting the industry shifted radically downward with the arrival of the second nationwide franchise chain. Introducing harsh price-based competition, it was those firms that had neither a high quality (restaurant style) nor highly efficient (franchise style) operations that felt the full weight of the selection forces. In this instance, a disruptive selection process quickly removed those situated in between the quality and price-based offerings. The most noticeable example of stabilizing selection accompanied the disruptive selection of those 
neither specifically quality nor operationally efficient operators whose management of cash flows nevertheless saw them favoured by the introduction of a (10\%) goods and services tax. Those that mismanaged their cashflow, irrespective of their market positioning, struggled to adapt to a market place that required tighter management of operating cashflow.

This section aims to consider what elements of a firm interact with the environment in such a way that the result is the differential selection of the firm's replicating entities. It has been recently argued (Jones, 2005) that at present there appears to be an absence of focus upon what element/s of the firm is interacting with the environment. If the position of Hodgson (2003a) is taken, and habits and routines are taken as replicators, the question remains, what interacts? Aldrich (1999) states that firms of all sizes are characterised by the following three dimensions: goal-directed behaviours, boundary maintenance, and activity systems. From this perspective, why and where interaction occurs is accounted for respectively by the firm's goals and boundaries. However, the activity systems of a firm cannot simply be considered as the interactor. Aldrich notes that activity systems are comprised of sets of routines and bundles of activities that facilitate the processing of raw materials, information and people. However, the question now arises, which activities are performed outside the firm and therefore interact with the environment, and which are performed inside and don't interact with the environment? This task is all the more important given that Hodgson (2003a) rightly points out that routines cannot be both the generative structures (i.e. replicators) and the outcomes of such structures (i.e. interactors). It is therefore necessary to remove any potential confusion as to what elements of a firm interact and which elements replicate.

Adapting Goffman’s (1959) dramaturgy approach, we can establish interaction boundaries using his frontstage, backstage metaphor. The frontstage represents the space 
where the firm's performance interacts with the environment, whereas the backstage represents the space where this performance is rehearsed, planed, designed and implemented. The use of the metaphor encourages exploration of the suggested relationship between the interacting elements and the environment. The challenge remains to separate front stage from back stage, and to define what was visibly offered for consumption by the firm. Just as important is to establish which backstage processes (despite their invisibility) determined the nature of the performance.

If this challenge is resolved, then we can move beyond assuming the firm's entire activity system interacts with its operating environment. We can see the proposition that the market selects and removes firms that have insufficient profits (Murmann, 2003), while true, is an after the event description of what has been selected. Given that markets are "in fact quite tolerant of underperformance" (Whittington, 1993: 24), going beyond a default to profits is necessary. It is more likely that specific elements of the firm's performance (rejected on the front stage) have caused insufficient profits. Therefore, a focus on interacting entities must move beyond activity systems, but not extend immediately to entire firms. What must be considered is the actual nature of what is offered for consumption. It has been proposed (Jones, 2005) that what constitutes the firm's offerings could be considered, a combination of activities that are delivered by humans and technologies, actual products and services, and the projected identity of the firm. These three elements, while not representing an exhaustive search for all possible offerings provide elements of focus. Through them, we can see how change is enacted within the firm through modification to existing goals, boundaries and activities, and we have material elements whose consumption (i.e. marketplace acceptance) can be measured. The firm's three interacting elements are now briefly considered in more detail. 
While a combination of activities that are delivered by humans and technologies seems broad in description, we can be more specific. This first element relates to all contact points through which the firm and its agents interact with all external stakeholder groups. The actual services and products the firm provides should require no further explanation as an element through which firm/stakeholder interaction occurs. The last proposed element is that of identity. Identity has previously been considered an interactor (Knudsen, 2002: 461) with regards to "the personal and professional identity of team members”. However, the proposed role of identity considered here is at the higher level of the firm itself. The literature tends to use the phase 'corporate identity' (Stuart, 1997) to describe corporate personality, which is based upon corporate strategy. Here, the term ‘corporate' will be used interchangeably with 'firm' to reflect the broad application of the evolutionary ideas expressed. Therefore, the identity of a firm embodies its culture and personality and a function of its interaction with external stakeholders is the firm's image. It is this image that influences the firm's fitness within its operating environment.

In going beyond profit as a factor directly selected for or against, other possible elements have been considered through which interaction with the environment may be better understood. This approach facilitates the separation of the processes that relate to interaction and replication. As will be discussed, a failure to do so would prevent the isolation of the specific processes that constitute a generative mechanism (i.e. mechanism of transmission), potentially subject to change through internal modification.

The major task according to Durham (1991: 24) is to identify what "governs the transmission of units [i.e. habits and routines] through space and time and either maintains or erodes variability”. That is, how can we explain the operation of entities that influence (and are differentially selected as a result of) the interacting elements of a firm? How can we account for the retention of current practices or the emergence of new practices, either 
of which may maintain, increase, or decrease overall fitness? Essentially what is being considered is an explanation of how the evolutionary process of variation, selection and retention occurs within the firm. Or, what learning capacity does a firm have (or not have), which in turn influence the composition of its interacting elements?

Campbell (1965: 27) states that if all components of the variation-selectionretention process are present, “a socio-cultural learning process is inevitable”. Learning is described within an organizational setting as, outcomes related to change via analysis or imitation, or, a process of adaptation dependent upon delicately balancing exploration against exploitation (March, 1991). This suggests that to achieve learning dependent outcomes, both variation and retention processes must relate to each, despite the inherent forces that alienate each from the other. The ability of firms to select new variations (or retain existing variations) clearly shapes the nature of their interacting elements. However, to use an adaptation of Aristotle's approach to the use of anger, any firm can change - that is easy. But to change the right activity systems, to the right degree, at the right time, for the right purpose, and in the right way - that is not easy. To further explore this issue, we need to consider Knudsen’s (2002) baseline idea.

Both sides of the selection - adaptation argument can be reconciled within Knudsen’s (2002: 453) baseline theory, given his assertion that the progress of knowledge through an adaptive process "requires a baseline through which the value of a possible modification can be evaluated”. Therefore, the firm's activity systems could represent behaviours that produce products and services, are responsible for the development of a firm's identity, and facilitate contact between the firm's systems (be they human of technological) and external stakeholders. In short, they are responsible for what occurs of the front stage. This performance is dependent upon the potential capabilities of the firm to plan, revise, and implement such behaviour. At anytime, the firm is in receipt of 
feedback from its audience. The market share achieved by products and services, the image present in the marketplace of the firm, and information received during contact between the staff and/or technological interface all represent substantial and ongoing feedback. This feedback should act to stimulate further planning, revision, and implementation of future performance. This activity is performed on the back stage and guided by the pressures of natural selection that are real and present on the front stage. This pressure should provide guidance to the adaptive intentions of the firm. The process of internal selection, a function of the habits and routines present within the firm, is ultimately judged by the audience on the front stage.

Just how such habits and routines combine to influence the composition of interacting elements remains largely a mystery. A developing approach (Jones, 2005) has been the overlaying of an existing conceptual framework to highlight the learning processes that connect back stage and front stage selection pressures. This has been attempted through consideration of Zahra and George's reconceptualization of the absorptive capacity construct. They define absorptive capacity as having two distinct components that together are operationalized as "a set of organizational routines and processes by which firms acquire, assimilate, transform, and exploit knowledge to produce a dynamic organizational capability” (2002: 186). Within this new definition are two specific components, potential (i.e. acquisition and assimilation) and realized (i.e. transformation and exploitation) absorptive capacity. Potential absorptive capacity is the capability to sense what information is relevant, acquire it, analysis it, comprehend it and internalise it. As such, it provides the firm an appreciation of the exogenous environmental forces that may or may not favour the firm's existing offerings. Realized absorptive capacity relates to the processes that blend existing knowledge with newly acquired knowledge to gain new insights to opportunities or problems and provide structured 
pathways to develop new competencies. In aggregate, the two components potential provide the foundation of "a dynamic capability pertaining to knowledge creation and utilization” (Zahra \& George, 2002: 185). When viewed from an evolutionary perspective, it is argued that this interpretation of the absorptive capacity construct supports discussion of how, why, and when individual firms learn about environmental change. The construct also seems to fit with Hodgson’s (2003a) habits and routines as replicators approach.

The four dimensions of absorptive capacity; acquisition, assimilation, transformation, and exploitation, can be seen to be present as potential behaviours. These potential capabilities are triggered by external or internal events that cause to the firm to respond to the stimuli. That is, the firm's ability to efficiently acquire and assimilate external knowledge is a function of their past capability to perform such behaviours under the same context and selective pressures. However, this learning potential only influences the firm's evolutionary potential (Jones, 2003) if all four dimensions coexist as a cohesive whole. Merely increasing awareness of variations does not endow the firm with the ability to maintain or increase the fitness of the interacting elements. Thus, the firm is subject to selection at two specific levels. First, the interacting elements face the pressures of natural selection, and secondly, this interaction results in the differential selection of the habits/routines that support the replicating processes within the firm. Given that firm's can acquire new characteristics from the marketplace, the firm's degree of potential absorptive capacity shapes up as critical to the process of adapting to market shocks and exploiting opportunities. Importantly, this capability is mediated by the degree of prior knowledge held across specific domains.

The four issues discussed thus far can be now brought together and their interrelatedness considered in more detail. In doing so the challenges that confront the development of a sound evolutionary approach to the study of entrepreneurship are again 
highlighted. This discussion can be assisted with reference to Figure 3, Replicating and Interacting Entities (over the page).

Insert Figure 3 about here

Within Figure 3, all the minimal elements of an evolutionary theory (as presented in Figure 2) are allowed for. A process of external selection is present that acts directly upon the firm's interacting elements. Such interaction creates the opportunity for feedback to be received via a baseline from which comparisons are made to existing perceptions of the firm and its marketplace. So, a means of (both internal and external) selection is present, sources of variation are accounted for through internal adjustments related to knowledge of and feedback form the marketplace, and retention is clearly possible through the maintenance of the firm's interacting elements. Individual habits that collectively form organizational routines responsible for the back stage learning processes that determine via the firm's activity system what are produced on the front stage are accounted for. Taken together, the habits and routines represent a generative mechanism responsible for the process of replication. As has been explain previously, the interactors are suggested to comprise the human and technological elements that provide contact points to the firm's stakeholders, the products and services on offer and the identity developed by the firm. The critical issue of what constitutes a mechanism of transmission has been addressed through discussion of a recurring learning process through which a firm can acquire, assimilate, transform and exploit knowledge that can increase its overall degree of fitness.

Figure 3 does not attempt to suggest a new theory of evolution. It merely attempts to bring together all the vital elements of an evolutionary theory into one model to provide 
a focus on the middle ground. It moves away from an assumption that the either the environment or the adaptive abilities of a firm provide a starting point for discussion of entrepreneurial behavior. It suggests that any such future discussion should be centred between those two viewpoints. As such, any conclusion regarding the outcomes of entrepreneurial behavior must be derived from proper consideration of the context and process of such behavior. The proposed model is therefore consistent with Aldrich and Martinez (2001) and satisfies the minimal requirements of any future evolutionary theory. The use of the construct absorptive capacity provides an example of how existing theory can be reconciled within an evolutionary approach, an essential feature of any future “evolutional model of organizational change” (Aldrich, 1999: 42).

\section{CONCLUSION}

Essentially, what has been discussed is a Darwinian framework that does not discriminate against other forms of evolutionary thought. A dovetailing of Darwinism and Lamarckism is not only consistent with Darwin's $6^{\text {th }}$ edition of The Origin of Species; it is also supported in the current literature (Hodgson, 2001) on the proviso that Darwinism provides the overall framework. It has being argued that much trouble can be avoided by those pragmatic evolutionary theorists who tackle the real (and unresolved) issues that prevent the development of a sound evolutionary theory of entrepreneurship. It is suggested that the interactor - replicator framework developed by Hull (1988), provides a simple way of understanding the breadth and depth of a Darwinian approach.

Baum and Singh (1994) in using Hull's framework, highlight three areas of consideration for the development of an evolutionary theory. They see organizational evolution as a process dependent upon various entities (e.g. habits, routines, firms, populations, and communities) that replicate and interact whilst a range of processes (e.g. 
copying, new enterprise, learning, and natural selection) occur during the specific events (e.g. start-up, transformation, and failure) in their life course. Their work is thought provoking and provides a pivotal stepping-stone worth revisiting. Figure 3 seeks to build upon such work by promoting a conceptual framework through which two kinds of processes (i.e. interaction and replication) can be seen to be connected to an entities desire to retain its form whilst always being capable of altering its form based on the ongoing feedback produced from ever occurring interaction. If it is reasonable to consider entrepreneurship as a function of the interaction occurring between human nature and the environment, then it is argued that Figure 3 provides a lens to observe the process of entrepreneurship.

The development of Figure 3 also serves to highlight the many questions that remain unanswered regarding an evolutionary theory of entrepreneurship. For instance, at what point are acquired characteristics inherited, and therefore representative of a Lamarckian process? To what extent is the nature and type of selection forces operating against the firm's interacting elements clearly understood? Which specific elements of a firm interact with the operating environment in such a way that they cause the differential selection of a firm's replicating entities? And lastly, what learning processes are observable that can be reconciled to the generic evolutionary process of variation, selection and retention? Within all these questions, an individual or team of individuals is assumed to be responsible for entrepreneurial behaviors, not firms. This position represents an acknowledgement that the majority of firms in the world are small firms with principals who have much responsibility regarding the process and ability to change direction. Tackling these questions and the many others that require attention (Aldrich, 1999) is but one step towards the development of a sound and legitimate evolutionary theory of entrepreneurship. 
One last concluding comment is that the literature sources used throughout this discussion represent an extreme synthesis of eclectic work. If this paper makes only the contribution of drawing attention to the need to consult beyond the comfortable boundaries of organizational theory, it will have made a valuable contribution. Contained within the above discussion are the thoughts of zoologists, sociologists, anthropologists, palaeontologists, philosophers, geneticists, and heterodox economists. Much care is required to bring together such seemingly disparate contributions and maintain contextual similarity. This may well be just one of the necessary challenges for those researchers who pursue the development of an evolutionary theory of entrepreneurship.

\footnotetext{
${ }^{1}$ Hodgson (2003a) notes the application to of Darwinian ideas outside the realm of biology had long been promoted by many prominent individuals, including Bagehot (1872), James (1880), Ritchie (1896), Peirce (1898), Veblen (1899, 1919), and Baldwin (1909).
}

${ }^{2}$ See Hodgson (2003a; 2001) regarding the respective merits of memes, ideas, habits, and routines as replicating entities.

${ }^{3}$ English engineer, Fleeming Jenkin demonstrated that Darwin's blending theory would not allow favourably selected biological traits to be inherited. Darwin's $6^{\text {th }}$ edition of The Origins of Species resurrected Lamarck's theory of acquired characteristics (Koestler, 1978, p 180), only for it to be again ignored by his followers.

${ }^{4}$ The advent of the Second World War saw negative attitudes associated to Spencer's social Darwinism incorrectly transferred to many Darwinian ideas and concepts.

${ }^{5}$ Hodgson (2001) and Knudsen (2001) maintain that the underlying casual structure of Lamarckian evolution is actually Darwinian in nature.

\footnotetext{
${ }^{6}$ The term 'acquired characters' is used in conjunction with Hull's (2001) insistence that within such a context they are only potentially inheritable in a metaphoric sense.

${ }^{7}$ It is recognised that Baldwin, Morgan and Osborn all simultaneously and independently presented ideas related to adaptive radiation.
}

\section{REFERENCES}

Aldrich, H.E. 1999. Organizations evolving. London: Sage Publications.

Aldrich, H.E., \& Martinez, M.A. 2001. Many are called, but few are chosen: An evolutionary perspective of the study of entrepreneurship. Entrepreneurship Theory and Practice 25(4): 41-56. 
Amburgey, T.L., Kelly, D., \& Barnett, W.P. 1993. Resetting the clock: The dynamics of organizational change. Administrative Science Quarterly 38(1): 51-73.

Amburgey, T.L., Dacin, T., \& Kelly, D. 1994. Disruptive selection and population segmentation: Interpopulation competition as a segregating process. In Evolutionary dynamics of organizations, Eds. Baum, J.A.C., and Singh, J.V., 240254. New York: Oxford University Press.

Amit, R., Glosten, L., \& Muller, E. 1990. Entrepreneurial ability, venture investing, and risk sharing. Management Science 36(10): 1232-1245.

Baldwin, J.M. 1896. A new factor in evolution. American Naturalist 30(June-July): 441451.

Baum, J.A.C., \& Singh, J.V. 1994. Organizational hierarchies and evolutionary processes: Some reflections on a theory of organizational evolution. In Evolutionary dynamics of organizations, Eds. Baum, J.A.C., and Singh, J.V., 3-20. New York: Oxford University Press.

Brittain, J. 1994. Density-independent selection and community evolution. In Evolutionary dynamics of organizations, Eds. Baum, J.A.C., and Singh, J.V., 355378. New York: Oxford University Press.

Bruderer, E., \& Singh, J.T. 1996. Organizational evolution, learning, and selection: A genetic-algorithm-based model. Academy of Management Journal 39(5): 13221349.

Campbell, D.T. 1965. Variation and selective retention in socio-cultural evolution. In Social Change in Developing Areas: A Reinterpretation of Evolutionary Theory, Eds, Barringer, H.R., Blanksten, G.I., and Mack, R.W., 19-49. Cambridge: Schenkman Publishing.

Darwin, C. 1901. The origin of species by means of natural selection. London: J. Murray.

Dawkins, R. 1983. Universal Darwinism. In D.S. Bendall. (Ed.), Evolution from molecules to man. 403-425. Cambridge: Cambridge University Press.

Davidsson, P., Low, M.B., \& Wright, M. 2001. Low and MacMillan Ten years on: Achievements and future directions for entrepreneurship research. Entrepreneurship Theory and Practice 25(4): 5-15.

Deacon, T. 1999. The symbolic species. New York: W.W. Norton.

Dollimore, D. 2003. Universal Darwinism in Nelson and Winter's evolutionary theory. Paper presented at the EAEPE Conference on the Information Society, Maastricht, 7-10 November 2003, http://www.eaepe.infonomics.nl/papers/Dollimore.pdf. 
Donaldson, L. 1988. In successful defence of organization theory: A routing of the critics. Organization Studies 9(1): 28-32.

Durham, W.H. 1991. Coevolution: Genes, culture, and human diversity. California: Stanford University Press.

Goffman, E. 1959. The presentation of self in everyday life. Garden City, NY: Doubleday.

Gould, S.J. 2002. The structure of evolutionary theory. London: Harvard University Press.

Grant, V. 1985. The evolutionary process: A critical review of evolutionary theory. New York: Columbia University Press.

Hamilton, D.B. 1953. Newtonian classicism and Darwinian institutionalism. Albuquerque: University of New Mexico Press.

Hannan, M.T., \& Freeman, J.H. 1997. The population ecology of organizations. American Journal of Sociology 82(5): 929-963.

Hayek, F.A. 1988. The fatal conceit: The errors of socialism, vol 1 of collected works of F.A. Hayek. London: Routledge.

Hodgson, G. M. 1993. Economics and evolution: Bringing life back into economics. Cambridge, UK: Polity Press.

Hodgson, G.M. 2001. Is social evolution Lamarckian or Darwinian. In Darwinism and Evolutionary Economics, Eds. Nightingale, J., and Laurent, J., 87-120. Cheltenham, UK: Edward Elgar.

Hodgson, G.M. 2003a. The mystery of the routine: The Darwinian destiny of an evolutionary theory of economic change. Revue Economique 54(2): 355-384.

Hodgson, G.M. 2003b. Darwinism and institutional economics. Journal of Economic Issues 37(1): 85-97.

Hull, D.L. 1988 Science as a process: An evolutionary account of the social and conceptual development of science. Chicago: University of Chicago Press.

Hull, D.L. 2001. Science and selection. New York: Cambridge University Press.

Hull, D.L., Langman, R.E., \& Glenn, S.S. 2001. A general account of selection. In D.L. Hull. Science and selection: 49-90. New York: Cambridge University Press.

Jones, C. 2003. Beyond e-commerce: When caterpillars know what butterflies understand. Journal of New Business Ideas and Trends 1(2): 10-20.

Jones, C. 2005. Firm transformation: Advancing a Darwinian perspective, Management Decision, 43: 13-25. 
Koestler, A. 1978. Janus: A summing up. New York: Random House.

Knudsen, T. 2001. Nesting Lamarckism with Darwinian explanations: Necessity in economics and possibility in biology. In Darwinism and Evolutionary Economics, Eds. Nightingale, J., and Laurent, J., 121-159. Cheltenham, UK: Edward Elgar.

Knudsen, T. 2002. Economic selection theory. Journal of Evolutionary Economics 12(4): 43-470.

Lamarck, J-B. 1984. Zoological Philosophy: An Exposition With Regard to the Natural History of Animals. Chicago: The University of Chicago Press.

Lewontin, R.C. 1970. The units of selection. Annual Review of Ecology and Systematics 1: $1-18$.

Levinthal, D.A. 1991. Organizational adaptation and environmental selection: Interrelated processes of change. Organization Science (1)2: 140-145.

Lewin, A.Y., \& Volberda, H.K. 1999. Prolegomena on coevolution: A framework for research on strategy and new organizational forms. Organization Science 10(5): 519-534.

Low, M.B., \& MacMillan, I.C. 1988. Entrepreneurship: Past research and future challenges. Journal of Management 14(2): 139-161.

Lumsden, C.J., \& Singh, J.V. 1990. The dynamics of organizational speciation. In Organizational evolution: New directions, Ed. Singh, J.V., 145-163. London: Sage Publications.

March, J.G. 1991 Exploration and exploitation in organizational learning. Organization Science 2(1): 71-87.

Miles, R.E., \& Snow, C.C. 1994. Fit, failure, and the hall of fame: How companies succeed or fail. New York: Free Press.

Murmann, J.P., \& Tushman, M.L. 2001. From the technology cycle to the entrepreneurship dynamic: The social context of entrepreneurial innovation. In The entrepreneurship dynamic: Origins of entrepreneurship and the evolution of industries, Eds. Schoonhoven, C.B., and Romanelli, E., 178-203. California: Stanford University Press.

Murmann, J.P. 2003. Knowledge and competitive advantage. New York: Cambridge University Press.

Nelson, R.R., \& Winter, S.G. 1982. An evolutionary theory of economic change. Cambridge: Harvard University Press.

Rao, H. 1998. Caveat emptor: The construction of nonprofit consumer watchdog organizations. American Journal of Sociology 103(4): 912-961. 
Stuart, H. 1997. Exploring the corporate identity / corporate image interface: An empirical study of accountancy firms. Journal of Communication Management 2(4): 357373.

Plotkin, H. 1993. Darwin machines and the nature of knowledge. Cambridge, MA: Harvard University Press.

Rescher, N. 1977. Methodological pragmatism: A systems-theoretic approach to the theory of knowledge. New York: New York University Press.

Veblen, T. 1919. The place of science in modern civilisation and other essays. New York: B.W. Huebsch.

Waddington, C.H. 1969. Paradigm for an evolutionary process. In Towards a theoretical biology, Ed. Waddington, C.H., 106-128. Edinburgh: Edinburgh University Press.

Whittington, R. 1993. What is strategy - and does it matter? London: Routledge.

Wilkins. J.S. 2001. The appearance of Lamarckism in the evolution of culture. In Darwinism and evolutionary economics, Eds. Nightingale, J., and Laurent, J., 160183. Cheltenham, UK: Edward Elgar.

Williams, G.C. 1996. Adaptation and natural selection: A critique of some current evolutionary thought. New Jersey: Princeton University Press.

Zahra, S.A., \& George, G. 2002. Absorptive capacity: A review, reconceptualization, and extension. Academy of Management Review 27(2): 185-203. 
Figure 1

The System Requirements for Evolution

1. Units of Transmission

2. Sources of Variation

3. Mechanisms of Transmission

4. Processes of Transmission

5. Sources of Isolation

Source: Durham (1991: 22) 
Figure 2

Prerequisites of an Evolutionary Theory

\begin{tabular}{|l|cc||c|c||c|}
\hline & Innovation, & Natural & Inheritance & Habits & Questions \\
\hline & Imitation, \& & Selection \& & Replication & $\&$ & Remaining \\
\cline { 2 - 5 } & New Entrants & Adaptation & \& Boundaries & Routines & Unanswered \\
\hline Campbell & Variation & Selection & Retention & & \\
\hline Lewontin & Phenotypic & Differential & Heritable & & \\
& Variation & Selection & Fitness & & \\
\hline Durham & Sources of & Process of & Sources of & Units of & Mechanism of \\
& Variation & Transmission & Isolation & Transmission & Transmission \\
\hline Hull & & & & Replicators & Interactors \\
\hline
\end{tabular}


Figure 3

Replicating and Interacting Entities

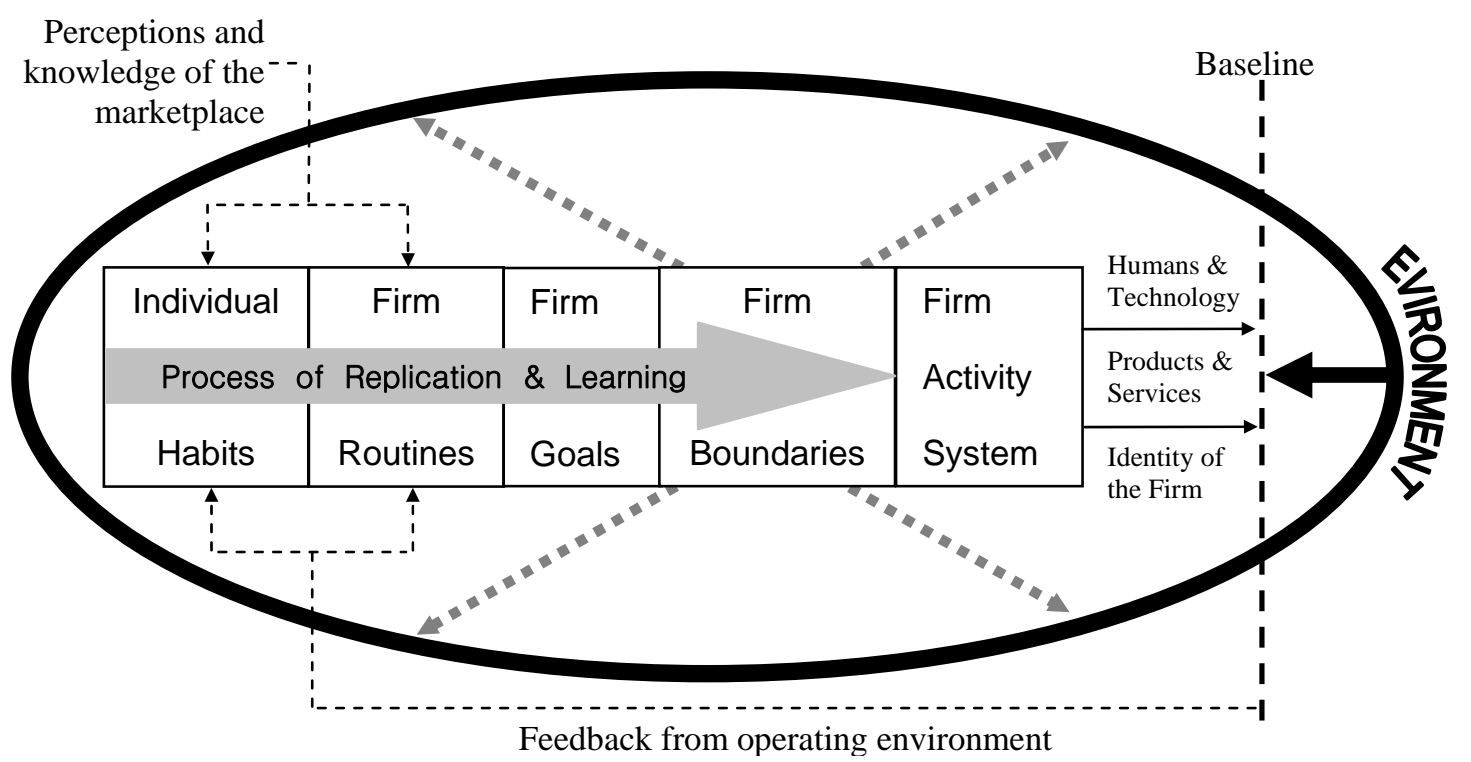

